\title{
ACOCORÉ: UM PROJETO DE RESISTÊNCIA À PANDEMIA OU ARTE EM TEMPOS DE TELEPRESENCCA
}

Acocoré: a pandemic resistance project or art in times of telepresence

Acocoré: un proyecto de resistencia a la pandemia o arte en tiempos de telepresencia

> Maria Beatriz de Medeiros [Universidade de Brasília, Brasil]*

Citação recomendada: MEDEIROS, Maria Beatriz de. Acocoré: um projeto de resistência à pandemia ou arte em tempos de telepresença. Revista Poiésis, Niterói, v. 22, n. 38 , p. 266-278, jul./dez. 2021. [https://doi. org/10.22409/poie-

Este documento é distribuído nos termos Commons AtribuiçãoNão Comercial 4.0 Internacional [CC-BYNC] (C) 2021 Maria Beatriz de Medeiros

(Submetido: 15/1/2021

Aceito: 13/5/2021

Publicado: 7/7/2021) sis.v22i38.48172] da licença Creative

RESUMO O presente texto apresenta o projeto Acocoré [Arte, Coletivos, Conexões e Redes] realizado em telepresença desde julho de 2020, isto é, durante uma pandemia. Acocoré foi uma ideia, um movimento, e, de repente, [e]vento: site, performances, entrevistas, vídeos, isto é, movimento disruptivo fazendo História. PALAVRAS-CHAVE Acocoré, arte, coletivos, conexões, redes

ABSTRACT The following paper presents the Acocoré project [Art, Colectives, Connections and Networks], conceived and carried out online and over telepresence since July 2020, during the pandemic. Acocoré was an idea, a movement, and suddenly is [e]vent: website, performances, inter-actions, videos, therefore disruptive moviment making history.

KEYWORDS Acocoré, art, collectives, connections, networks

RESUMEN Este texto presenta el proyecto Acocoré [Arte, Colectivos, Conexiones y Redes] realizado en telepresencia desde julio de 2020, es decir, durante una pandemia. Acocoré fue una idea, un movimiento y, de repente, [e]viento: web, performances, entrevistas, videos, es decir, un movimiento disruptivo que hace historia. PALABRAS CLAVE Acocoré, arte, colectivos, conexiones, redes

* Maria Beatriz de Medeiros é professora do Departamento de Artes da Universidade de Brasília - UnB, Doutora em Arte e Ciências da Arte pela Universidade Paris I e coordena o Grupo de Pesquisa Corpos Informáticos desde 1992. E-mail:mbmcorpos@gmail.com, ORCID: https://orcid.org/0000-0003-1899-1052 
De repente, o silêncio. Não mais "teatro, boate, cinema" [Luiz Melodia, Congênito]. De repente, o pouco que se tem representa tudo e/ou o muito que se tinha se fechou. A vida cessou nas ruas. Não mais carros e ônibus, desde às seis horas da manhã, arranhando o sono pouco de quem muito correu. O sono se esparrama junto com o medo. Silêncio: ninguém vai chegar e ninguém vai sair. Não haverá convites, nem vernissages, nem aniversários, nem almoços familiares, nem viagens, hotéis ou outras paisagens.

O COVID 19 tomou a vida de muitos no momento em que escrevo, janeiro de 2021. O COVID 19 tomou a vida de 1\% da população brasileira. Presa em casa, 50\% da população, e o vírus passeando nas ruas, calçadas, praias e parques. Os teatros escuros e fechados ruminando mofo e poeira em poltronas tortas; as boates silenciosas e ninguém cheirando nos banheiros, os cinemas surdos, cegos e mudos com portas enferrujando. Os museus e galerias de arte acumulando um vazio de sentido de obras de arte enclausuradas. A arte se completa na interação e/ou na iteração. ' Sem ser vista, ela é, naturalmente, invisibilizada, mas também inviabilizada. Um papel cheio de pontos, de linhas e de tintas, nada pode dizer em uma gaveta, mofando. Um grito não escutado escorre pelas paredes mudas e a performance congela o artista na geladeira que estala, range, mas não interage nem iterage.
Assim foi se passando o inesquecível ano de 2020, se arrastando entre paredes ou brilhando, um pouco, nos 15 minutos em que o sol toca janelas, na cerveja solitária ao final do dia surdo, em intermináveis séries televisivas agora esgotadas: ninguém filma, ninguém atua, ninguém monta cenários que permitiriam outros devaneios para longe deste confinamento. Com fim? Não sabemos, mas certamente, lamento.

14 dias, 30 dias, 60 dias. No meio da solidão, julho de 2020, uma mensagem. Tratava-se de um convite para fazer uma sequência de fotos sobre máscaras feito por Juliana Cerqueira, pessoa que não via há mais de dez anos, que havia colaborado em alguns trabalhos em arte e tecnologia, isto é, em performance em telepresença do Grupo de Pesquisa Corpos Informáticos ${ }^{2}$, que coordeno desde 1992. Resolvi telefonar e questionar, ao que me foi respondido que era uma proposta inicial ainda sem rumo definido. Assim, fizemos uma "simples" sequência de fotos.

Me adianto no texto para não deixar os leitores inquietos: Acocoré é hoje, janeiro de 2021, a meIhor coisa que fizemos, Juliana e eu, mas também todos aqueles que vêm participando deste projeto: ele mudou nossas vidas, ele nos dá felicidade, risadas, danças, trocas, comédias, debates sérios, [e]vento, e uma infinita coleção de figurinhas 
no WhatsApp. Temos performances coletivas aos sábados no Zoom, nas quartas-feiras temos o projeto Entre-atos, nunca entrevistas no Instagram, nas segundas-feiras vamos começar um grupo de estudos, temos um site [criado e alimentado por Juliana Cerqueira: https://acocore.wixsite.com/acocore] e cerca de 300 mensagens no WhatsApp por dia: conversa séria: 2\%; diversão, comédia, brincadeira, palhaçada crítica: 98\%. Temos, inclusive, uma marca.

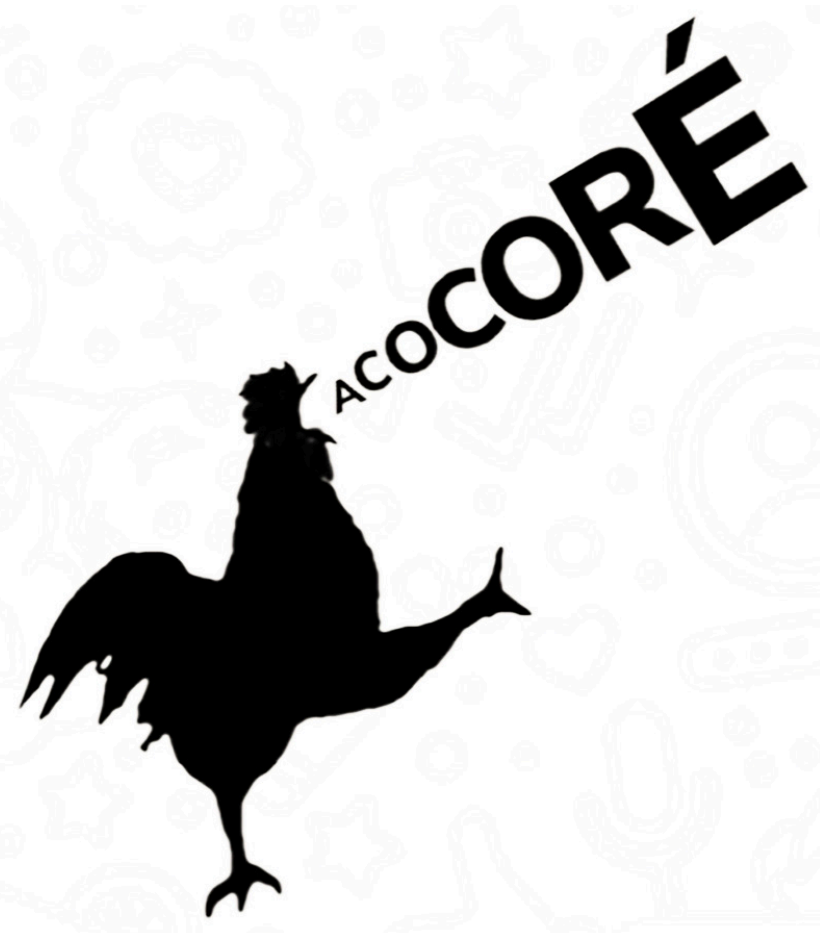

Acocoré nasceu Arte, Coletivos, Conexões e Redes em 18 de julho de 2020 com a performance Descobrindo Máscaras. Como dito, desde esta data temos performado todos os sábados pelo Zoom. À cada performance, corresponde um título, um texto e uma imagem e/ou vídeo que convida para a ação [criação e design: Juliana Cerqueira]. Somos, em ordem alfabética: Ana Reis [GO]; Alex Simões [BA]; Arthur Scovino [RJ, BA, SP]; Bia Medeiros [RJ, DF]; Carla Rocha [DF, USA]; Cássia Nunes [GO]; Cristine Carvalho Nunes [RS]; Juliana Cerqueira [RJ]; Maíra Vaz Valente [SP]; Milene Lopes Duenha [SC, PR]; Raphael Couto [RJ]; Ricardo Garlet [SC]; Zélia Caetano [PR]; Zmário [José Mário Peixoto. BA]. Alguns destes artistas conhecemos pessoalmente e/ou realizamos trabalhos em grupo, outros foram aparecendo e se tornando parte deste movimento, digamos, necessário. Alguns participam desde o início, outros acocoraram há pouco, outros observam sem nos deixar vê-los, outros pululam por lá.

Fig. 1 - Logomarca do Projeto Acocoré.

Fonte: Arquivo Bia Medeiros, https://acocore.wixsite.com/acocore. 


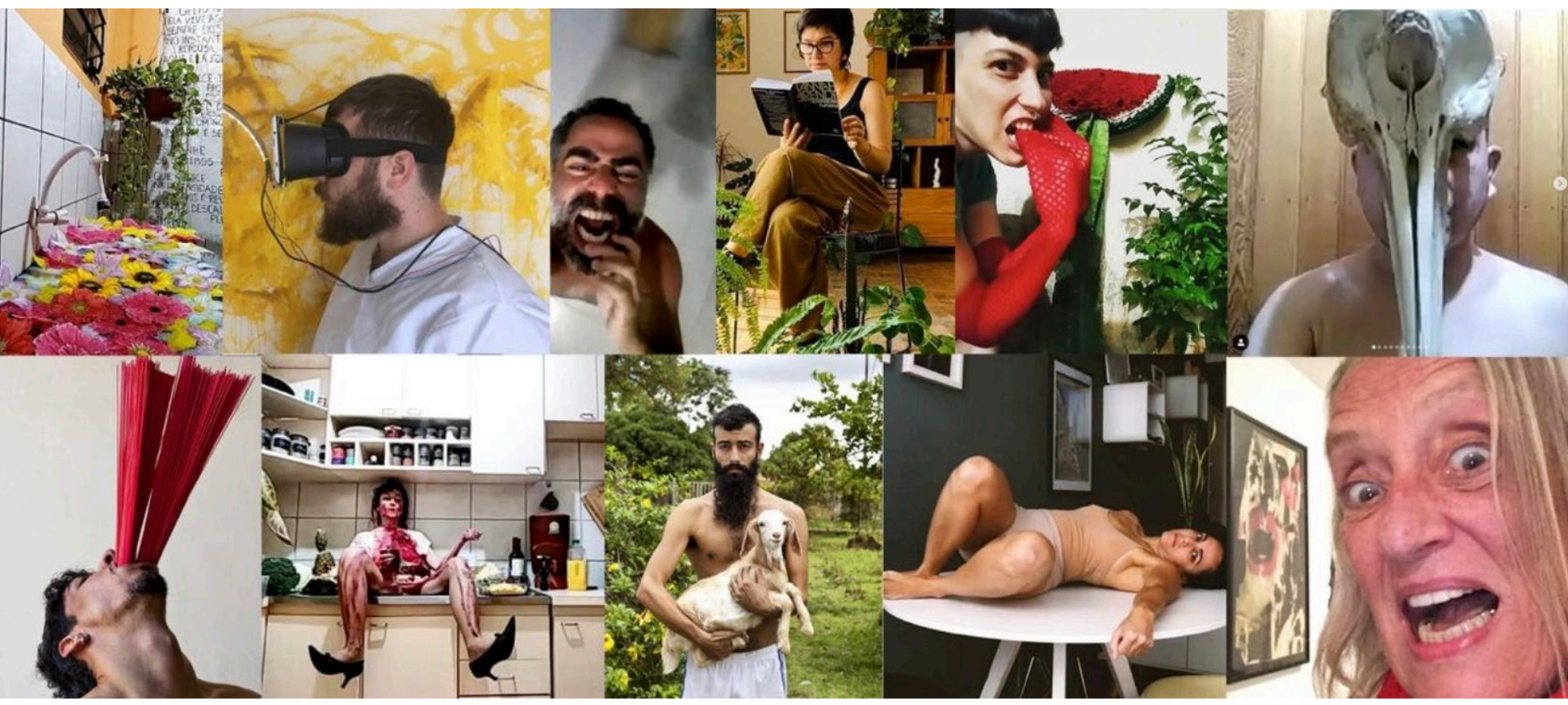

Fig. 2 - Acocoré, Grupo, 2021, performance. Fonte: Arquivo Bia Medeiros, https://acocore.wixsite.com/acocore

Da esquerda para a direita, de cima para baixo: Enquanto isso na pia [Naldo Martins]; Ricardo Garlet; Zmário; Maíra Vaz Valente; Cássia Nunes; Naldo Martins; Raphael Couto; Milene Lopes Duenha; Arthur Scovino; Juliana Cerqueira; Bia Medeiros. Fonte: https://www.instagram.com/artecoletivosconexoes/ 
Acocoré é oxigênio com que o galo enche o peito para cantar toda manhã. É o som do respiro da tartaruga na superfície do mar aberto. É o chão da plataforma suspensa na nuvem criada para promover encontros virtuais, performáticos e simultâneos de corpos aflitos que se estrebucham na terra em chamas.

@arthurscovino [Arthur Scovino, SP, 04/10/2020]

Acordar no espelho das nossas sombras voláteis. Poesia bordada dos sentidos. Uns lá e eus aqui. Textura de espaços e tempos, tautocronia. Renda preciosa, colcha de retalhos de uma memória desejada. Música rebelde dos desejos. Teletransporte do sopro, toque.

@carlarocha [Carla Rocha [RJ, DF, USA]

Acocora a vida, o mundo, o tempo que vai passando, num pequeno instante de nós captado. Nosso sexo, desejos à flor da pele, na pele película do corpo, da tela, do vídeo. Exposto, entregues ao devir do agora, do já, na potência que move os corpos. Conexões onde corre eletricidade, afeto, água de rio, mar, extinguindo distâncias na imensidão do existir.

@nau_vegar [Naldo Martins. AP, 08/10/2020]

Uma ideia,

Um movimento,

E, de repente, vento.

Um tormento, um lamento

E, sem muito, evento.

Um retorno entardecido,

Talvez, distorcido, talvez,

Inacabado, no tempo mutilado.

Eu, magia;

Tu, vida;

Ela, existência;

E nós, nós, nós,

E eles e elas e outros também:

Acontecimento.

@performancecorpopolitica [Bia Medeiros. RJ, 13/10/2020]
Em outubro de 2020, solicitamos aos participantes textos sobre o Acocoré: ${ }^{4}$ Como dito, cada performance aos sábados possui título e texto, cada um sugerido por um de nós. Eles são propostos, mas quase nunca seguidos. Performances todos os sábados! Haja repertório e, em tempos de pandemia, é praticamente impossível perseguir propostas: em geral, trabalhamos com o que temos em mãos, nossos corpos, objetos, animais gatos, cachorros, pássaros fazendo ninho na cozinha, e até cavalos], trabalhamos com nossas pias sempre de novo e de novo lotadas. Alguns lavam banheiros, poucos passeiam. 


\section{Panos/Plumas/Revoltas e ironia. 25/07/2020}

$\begin{array}{lll}\text { Panos } & \text { Plumas } & \text { Revoltas e ironia. } \\ \text { Planos } & \text { Puros } & \text { Reflexos e zombarias. } \\ \text { Plenos } & \text { Puns } & \text { Recuerdos e zunzunzu } \\ \text { Planaltos } & \text { Praias } & \text { Resenhas e fuleragem } \\ \text { Prumos } & \text { Pontas } & \text { Ritmos e mares. } \\ \text { Tortas } & \text { Portas } & \text { Ratos e maresias. } \\ \text { Desvios } & \text { Devaneios } & \text { Romarias e rosáceas. } \\ \text { Pontes } & \text { Padrões } & \text { Rendas e distância. }\end{array}$

Demônios meus Desejos nossos Recados outros

Emendas

frouxas

Paralelos Convexos E triângulos amorosos.

População perplexa Poderes não mais podres

Mas Purulentos Assassinos.

Povo preso, Povo e medo.

Revolta Discórdia $70 \%$ \#elenão.

FORA Ferro Muita tristeza e hospitais lotados.

FORA. Foda. Foda-se.

ARTE ARTE ARTE (dito como se ladrasse).

[Texto proposto por Bia Medeiros em 25/07/2020]

\section{Desengaiolar em durAÇÃO. 10/10/2020}

Desengaiolar a pele que não toca. Desengaiolar as mônadas, fênix, minotauros e seres mágicos..

"O que pode o corpo?": tudo e nada.

Corpo engaiolado. Corpos atravessados por linhas duras, às vezes flexíveis, mas certamente caóticas, malcriadas.

Surge em frestas o desengaiolar constantemente, urgindo como o vento, rasgando o grito e a palavra. Desengaiolar as mônadas, compor com os corpos, confabular com as gotas do oceano, em durAÇÃO, ultrapassar as dimensões do cabível.

A experiência é coletiva. Habitamos vários nós e derivantes, cambiantes, embriagantes. Mover as grades da gaiola, convocar corpos para o experimento ao beijar a terra, descer e subir camadas. Encontrar a morte com vestes na ressonância da poesia da vida... Abrir a gaiola dos loucos, encontrar um lugar de nó (s).

Enfim, sem fim. O gozo vital.

Bem vind@s!

\section{Astrolábio de sete faces ( $6^{\mathrm{a}}$ face). 28/11/2020}

Fórmula: sangue, saliva, fio de cabelo ou sêmen, líquido amniótico, ossos, face, cu, dentre outros tecidos, entulho de amante, musa, silêncio, problemas, oxigênio, tapa-buraco, permissão progressiva, triz, sigilo, troca de segredos, treda ao lado, tecnologia, contas para viver melhor, conexos e conexões, odum, incêndio, puta dor, fúria e alta tensão no mundo, todos temos. No meu corpo, o canto.

[Texto proposto por Alex Simões. 28/11/2020]

As performances aos sábados são simultâneas: "cada um no seu quadrado" ou retângulo, por vezes entrando em conjunção com uma das ações de outros artistas. Por vezes, todos entram em uma mesma vibração, na mesma cor, em movimentos semelhantes 5 . Por vezes, não há consonância, mas "a potência caótica na criação de pequenas maquinarias do heterogêneo" [RANCIĖRE, 2012, p. 66]. EStamos fazendo arte [sempre lido como quem late], poesia, histórias e História: "O espaço do choque e do contínuo pode ter o mesmo nome, História. De fato, a História pode ser duas coisas contraditórias: a linha descontínua dos choques reveladores ou o contínuo da copresença" [RANCIĖRE, 2012, p.70].

Assim se expressou Zmário [José Mário Peixoto Santos] no WhatsApp:

[Texto proposto por Cristine Carvalho Nunes. 10/10/2020] 
Reflexões matutinas: não noto que apresento performances via Zoom... vejo que improviso em telepresença, como nas aulas de Improvisação em Dança, na Escola de Dança da UFBA, quando levávamos [...] objetos para performar [e as músicas tocadas davam o tom das ações]. Performance, para mim, requer uma determinada elaboração mesmo que o ensaio nunca ocorra... Leio os txts propostos para o encontro no Zoom, ficam reverberando no meu cabeção, separo alguns objetos que se aproximam simbolicamente dos conteúdos dos txts minutos antes, ligo a cam, e os aciono de maneira improvisada... Então, ao meu ver/ sentir, me apresentar no Acocoré é um exercício contínuo de improvisação em performance, ou seja, é por em primeiro plano e em prática um dos elementos característicos da performance: o improviso.

O projeto Entre-atos, nunca entrevistas, no Instagram, às quartas-feiras, foi inicialmente pensado no sentido de gerar uma maior iteração entre dois artistas, e havia, sobretudo, a intenção de fugir do formato de entrevistas que foi intensificado em diferentes projetos artísticos durante a pandemia. Estávamos cansadas de entrevistas com carinhas: duas carinhas falando em discursos muitas vezes entediantes: somos artistas! Como não poderia ser diferente, "voluímos"6 para um formato outro: um artista coordena a sala do Instagram e convida aleatoriamente qualquer um de nós, a qualquer momento. Esta iniciativa gera como que programas televisivos [engraçadíssimos] com convidados improvisando. O formato se revela cansativo para aquele que "orquestra" e também para os convidados, que permanecem em performance por 40 min tendo direito a "entrar em cena" de 3 a 15 minutos, no entanto, cria uma imensa diferença, ou melhor, dessemeIhança: "As imagens da arte são operações que produzem uma distância, uma dessemelhança" [RANCIĖRE, 2012, p. 15].

Há necessidade de citar também a proposta de ensaio. Em polêmica gerada no WhatsApp, que denominamos "polenta", discutimos diversas questões da performance. Entre elas, questões que sempre voltam quando se trata de performance. Por exemplo, o próprio questionamento sobre o que é performance. Em 2010, após uma visita às exposições Marina Abramovï [MoMA, NY, 2010] e 100 years of performance no PS1, ao retornar ao Brasil, discuti com o grupo Corpos Informáticos sobre o fato da performance "já" estar nos museus, isto é, ter se tornado doce [SERRES, 2005], se tornado linguagem. A conversa nos levou à necessidade de um novo termo para a performance e declaramos não mais fazer performance, mas fuleragem e, ainda, não mais realizar arte efêmera, mas fazer coisa mixuruca. A fuleragem pode ser barbárie, pode ser vagabunda, pode ser invertebrada, nego fugido, indolente, relaxado, mas não subserviente. A troça e a trapaça estão aí subentendidas. A ironia e o cinismo podem ser 
estratégias. Acocoré, no mesmo sentido, preferiu, não mais fazer performance, mas unicamente ensaio. No ensaio podemos errar,

ser errantes, corpo sem órgãos, matilha ou movimento. Performance, fuleragem ou ensaio? "Proust

chama essa desfiguração de denominação, qualificando a arte da sensação pura em Elstir: 'Se Deus Pai criara as coisas nomeando-as, era tirando seu nome ou dando-Ihes outro que Elstir as recriava.'" [RANCIËRE, 2012, p. 88].7

Outra questão foram algumas possibilidades da performan-

ce, do ensaio, ou da fuleragem, que divergem das nossas. Possibilidades: 1 - o artista idealiza e realiza a performance com seu corpo; 2 - o artista idealiza e realiza a performance com seu corpo e, posteriormente, paga alguém para refazer a performance [re-performance, exemplo: Marina Abramovic no Museum of Modern Art, NY, 2010]; 3 - o artista idealiza a performance e paga alguém para realizar a performance por ele. A isto podemos chamar "performance terceirizada" [exemplos: Ayrson Heráclito em Transmutação da carne em MAI Terra Comunal, SESC-SP, 2015, ou Laura Lima].Afirma Laura Lima:
Neste questionamento, outros artistas foram postos em questão: Francis Alys e seu movimento de montanha, Tania Brughera e Ana Mendieta, Santiago Serra, Tino Seghal, mas como afirma Zmário em polenta no WhatsApp: "não tenho opinião formada".

Corpos Informáticos, por diversas vezes, se tornou e se autodenominou Corpos Expandidos ${ }^{9}$. Trata-se uma prática diferente das acima citadas. Corpos Informáticos, desde 2010 principalmente, idealizou movimentos e/ou ações, sempre no improviso, isto é, recolheu, amaciou, tratou objetos, mas também camisetas [no sentido de formar visualmente um grupo maior] e propôs performances livres a outros 
Somos sensíveis, agora, muito sensíveis à telepresença, ela constitui, para nós enclausurados pelo coronavírus, as nossas próprias histórias e a História. E nós, acocoréticos brasileiros, enclausurados e desgovernados, nos lambuzamos de tecnologia para sermos nós mesmos, isto é, corpos desejantes vazando por telas e escapando da monotonia, da covardia, da hegemonia de um Estado falido, decrépito e agonizante.

Não tenho certeza se Acocoréé um grupo, um espasmo, um refúgio, um lapso, um sopro ou um porto, mas com certeza tem sido porta para outros devires, sonhos por outros espaços, lance de felicidade, fagulha de delícia e um bocado de risada.

De repente, o silêncio. Não mais "teatro, boate, cinema" [Luiz Melodia, Congênito]. Acocoré, segundas [teoria] e quartas-feiras [cinema] e sábados [festa]. A vida cessou nas ruas, nas telas pulula, dança e ri. Desde às seis horas da manhã, carros e ônibus voltaram, mas lá fora o medo permanece. Silêncio: ninguém vai chegar e ninguém vai sair: Acocorévai mandar 247 mensagens e muitas delas serão conforto, discussão, palhaçada ou zombaria. Haverá convites, vernissages, aniversários, almoços, viagens, hotéis e outras paisagens nas veias de um coletivo disruptivo e simultaneamente coeso.

Sejam bem-vindos! 
1 A iteração é o processo que acontece quando existe, em performances abertas à participação do público, à participação de transeuntes e/ou errantes [que somos todos nós], à efetiva participação. Por iteração entendemos, com Jacques Derrida [1990, p. 7 e 120]: "Iterabilidade- [iter, provavelmente vem de itara, outro em sânscrito, e tudo o que se segue pode ser lido, o trabalho fora da lógica que liga a repetição à alteridade] [...] A iterabilidade altera, parasita e contamina - que ela identifica e permite repetir; faz com que se queira dizer [iá, sempre, também] algo diferente do que se quer dizer, diz-se algo diferente do que se diz e gostaria de dizer, compreende-se algo diferente etc". Na iteração, a performance proposta pode e deve se modificar, se contaminar, ser outra pela participação dos outros.

2 Grupo de Pesquisa Corpos Informáticos, formado na Universidade de Brasilia em 1992: www.corpos.org; www.performancecorpopolitica.net; www.corpos.blogspot.com.br.

3 Disponível em: https://www.instagram.com/artecoletivosconexoes/

4 Para todos os textos conferir: https://www.instagram.com/ artecoletivosconexoes/

5 Todas as performances são gravadas e posteriormente editadas por Juliana Cerqueira. Os vídeos editados possuem cerca de 7 minutos e estão postados no site do Acocoré: https: / /acocore.wixsite.com/acocore.

6 "Volução" é outro conceito por mim desenvolvido: volução não é evolução, nem devolução, nem involução. $\mathrm{Na}$ volução não há progresso nem novidades. Nada é novo, tudo volui, re-volui. Há volução, processos em voluta, em espiral rodando sem objetivo, sem jamais atingir o centro [inexistente], sem jamais manter um só movimento. A volução se aproxima da volúpia quando paixões deixam mentes-corpos tormando-se um corpus político de prazer em grupo. As fragatas planam em volução.

7 Elstir é um personagem do livro d'À la recherche du temps perdu de Marcel Proust. Elstir simboliza, para Proust, o pintor visionário, aquele que é capaz de ver o mundo com outros olhos, e, através dele, o romancista constrói seu pensamento sobre pintura.

8 José Carlos Rodrigues é professor-associado da PUC-Rio e professor titular de antropologia da UFF. Doutor em Antropologia pela Université Paris 7, mestre em Antropologia Social pelo Museu Nacional da UFRJ e graduado em Ciências Sociais e em Direito pela UFF.

9 Corpos Expandidos são amigos, próximos, artistas, iterałores, sempre dispostos a iteragir.

10 Performance, Corpo, Política e Tecnologia. Evento organizado pelo Grupo de Pesquisa Corpos Informáticos, 2010. Financiamento: MINC-Petrobrás. www. performancecorpopolitica.net 11 Participação, Performance, Política. Evento organizado pelo Grupo de Pesquisa Corpos Informáticos, 2010. Financiamento: REDES-Funarte. www.performancecorpopolitica.net 12 http://corpos.org; http://www.corpos.org/telepresence2/index.html; http://www.corpos.org/teleperformance/ index.html; http://www.corpos.org/ctrlCctrlC79/index.html; http://www.corpos.org/weblandart/Index.html. 
AQUINO, F. \& MEDEIROS, M. B. Corpos informáticos. Cidade, corpo, política. Brasília: PPG-Arte, 2011.

BARRETO, Lima. Os Bruzundangas. In Prosa Seleta. Rio de Janeiro: Nova Aguillar, 2001.

DERRIDA, Jacques. Limited inc a b c... In: Limited Inc. Paris, Galilée, 1990a, pp.61-197.

LIMA, Laura. Laura Lima. Enciclopédia Itaú Cultural, 2021. Disponível em: https://enciclopedia. itaucultural. org.br/pessoa215255/laura-lima. Acesso em 27/05/2021.

MEDEIROS, Maria Beatriz de. Sugestões de conceitos para reflexão sobre a arte contemporânea a partir da teoria e prática do Grupo de Pesquisa Corpos Informáticos. Art Research Journal. Brasil. V. 4, n. 1, p. 33-47, jan. / jun. 2017.

MEDEIROS, Maria Beatriz de. Plataforma virtual: Bia Medeiros. Disponível em http://grafiasdebiamedeiros. blogspot.com/. Acesso em 27/4/2021.

RANCIÈRE, Jacques. O Destino das imagens. Rio de Janeiro: Contraponto, 2012.

RODRIGUES, José Carlos. O Corpo na História/ José Carlos Rodrigues. - Rio de Janeiro: Editora Fiocruz, 1999.

SERRES, Michel. Os cinco sentidos. Paris: Grasset, 2005. 